\title{
Identidade e memória em Os rios profundos, de José Maria Arguedas
}

\author{
Identity and memory in Os rios profundos, by José Maria Arguedas \\ Flávio Reginaldo PIMENTEL* \\ Pontifícia Universidade Católica de São Paulo (PUC/SP) \\ Elizabeth CARDOSO** \\ Pontifícia Universidade Católica de São Paulo (PUC/SP)
}

\begin{abstract}
RESUMO: Este trabalho estabelece uma inter-relação da identidade cultural com a memória do personagem Ernesto, no romance Os rios profundos (1958), do escritor peruano José María Arguedas. O objetivo é traçar uma reflexão teórica, e para tanto mapear e compreender como tais conceitos (identidade cultural e memória) estão presentes na narrativa arguediana a partir do discurso memorialístico do narrador-personagem, considerando o tempo e o espaço ficcional. Ernesto passa por um processo de profundas e significativas mudanças, o qual é atravessado por devires que o deslocam de sua territorialidade, fazendo com que passe por um processo de múltiplos movimentos. A identidade do personagem vive em um terreno movediço composto por sua condição mestiça, híbrida, heterogênea. Abre-se um diálogo entre a literatura, a crítica literária, a filosofia e a sociologia apoiado em Bergson (1999), Canclini (2008), Candido (2002), Cornejo Polar (2000, 2003), Hall (2006), Glissant (2005), Ricoeur (2007), Paz (1981, 1989).
\end{abstract}

PALAVRAS-CHAVE: José Maria Arguedas. Os rios profundos. Identidade cultural. Memória. Cultura.

ABSTRACT: This work establishes an interrelation with the cultural identity and memory of the character Ernesto, in the novel Os rios profundos (1958), by peruvian writer José María Arguedas. The objective is to outline a theoretical reflection and to map and understand how such concepts (cultural identity and memory) are present in the arguedean narrative from the narrator-character's memorialistic speech, considering time and fictional space. Ernesto goes through a process of profound and significant changes, which is crossed by becoming that displaces it from its territoriality, making it go through a process of multiple movements. The character's identity lives on a shifting terrain composed by its mixed, hybrid, heterogeneous condition. A dialogue opens up between literature, literary criticism, philosophy and sociology. A dialogue opens between literature, literary criticism, philosophy and sociology supported by

\footnotetext{
* Professor do Instituto Federal do Pará campus Belém. Doutorando em Literatura e Crítica Literária pela Pontifícia Universidade Católica de São Paulo/PUC-SP. Mestrado em Letras pela Universidade Federal do Pará/UFPA. Graduação em Letras pela Universidade Federal do Mato Grosso do Sul/UFMS. É bolsista CAPES/PROSUC. E-mail: flaviorpimentel2014@gmail.com

** Professora e pesquisadora do Programa de Pós-Graduação em Literatura e Crítica Literária da PUC-SP. Pós-doutorado pelo Programa de Pós-Graduação em Literatura e Crítica Literária da PUC-SP. Doutorado pelo Departamento de Teoria Literária e Literatura Comparada da FFLCH-USP. Mestrado em Comunicação pela ECA-USP e graduação em Jornalismo pela UNESP. E-mail: elizabethpenhacardoso@gmail.com
} 
Bergson (1999), Canclini (2008), Candido (2002), Cornejo Polar (2000, 2003), Hall (2006), Glissant (2005), Ricoeur (2007), Paz (1981, 1989).

KEYWORDS: José Maria Arguedas. Os rios profundos. Cultural identity. Memory. Culture.

\section{Introdução}

Pensar a literatura latino-americana e sua formação vai além das definições e concepções teóricas e estilísticas de escolas e movimentos literários. Passa por entender o complexo processo histórico, social, econômico e cultural que ao longo de mais de quinhentos anos de ocupação, ocorreu nas terras ameríndias. Aliado a isso, deve-se considerar as civilizações, grupos étnicos e povos indígenas que existiam antes da chegada do branco europeu.

Muitos escritores contribuíram de forma significativa para a conformação de uma literatura com marcas da diversidade cultural existente no continente. Entre eles, encontra-se o peruano José María Arguedas (1911-1969). Há quem o classifique como integrante de um novo indigenismo e/ou um escritor regional. O conjunto de sua obra ultrapassa os limites de classificações estéticas e de movimentos e/ou escolas literárias desenvolvidas na América Latina.

José María Arguedas nasceu em 1911 em Andahuaylas, distrito do departamento de Apurímac, sul da Cordilheira dos Andes. Exerceu várias atividades, foi professor, mas também foi etnólogo, antropólogo, folclorista, ensaísta, além de exercer várias funções no serviço público. Arguedas publica seu primeiro livro Agua em 1935, formado por três contos: Agua, Los escoleros e Warma Kuyay. Em 1939, publicou o conto escrito em quéchua Runa Yupay. Seu primeiro romance foi Yawar Fiesta (1941) que tem como tema uma corrida de touros no estilo andino. Em 1954, Arguedas publica o conto Diamantes y Pedernales.

Em 1958 publica Los ríos profundos e em 1961 publica El sexto. No ano seguinte, em 1962 publica os contos A nuestro padre creador Tupac Amaru e La agonia de Rasu-Ñiti, contos em que Arguedas se aproxima cada vez mais da cultura andina e de seu modo de vida. Em 1964 publica Todas las sangres. Em 1966, Arguedas publica Oda al jet e em 1967 Amor Mundo y todos los cuentos. José María Arguedas deixa inacabado o livro El Zorro de Arriba y el Zorro de Abajo que foi publicado 
postumamente em 1971. Como docente universitário, ministrou aulas na Universidade Maior de São Marcos e na Universidade Agrária de Molina, onde em novembro de 1969, cometeu suicídio.

Arguedas também é autor de inúmeros textos literários publicados de forma isolada, bem como artigos científicos, de caráter antropológico e etnológicos, além de textos críticos, ensaios e correspondências. José María Arguedas é considerado como um dos escritores mais proeminentes da literatura peruana. Dessa forma, ele desempenha importante papel na construção e fortalecimento da literatura latinoamericana do século XX. O autor usa toda sua originalidade para interpretar a realidade, acrescentando além do valor estético, o valor histórico, social e cultural, escrevendo com propriedade, pois viveu a realidade do mundo andino.

O romance, Os rios profundos (1958) é emblemático e considerado pela crítica especializada como o melhor livro arguediano. A obra entrecruza temas que dialogam memória, imaginário, identidades. O crítico literário Ángel Rama (1974, 1982 apud REIS, 2005) aponta que "três operações fundamentais ocorrem no interior das narrativas por ele consideradas transculturais; o uso da língua, a estruturação literária e a cosmovisão" (REIS, 2005, 471). Dessa forma, o crítico define alguns autores que possuem tais características, além de Arguedas, também o colombiano Gabriel Garcia Márquez, o mexicano Juan Rulfo e o brasileiro Guimarães Rosa.

Pretende-se abordar como são apresentados no texto literário a identidade cultural e a memória, a partir do discurso do narrador-personagem. No primeiro capítulo, uma passagem apresenta Ernesto rememorando o lugar de sua infância: "Eu não me sentia mal nesse quarto. Era muito parecido com a cozinha em que fora obrigado a viver na infância, com o quarto escuro onde recebi os cuidados, a música, os cantos e o falar dulcíssimo das criadas índias e dos concertados" (ARGUEDAS, 2005, p. 11).

Percebe-se na narrativa um constante movimento do personagem para construir sua identidade cultural a partir das experiências vividas. Ernesto vive as agruras de ser considerado mestiço/híbrido em uma sociedade marcada pelo preconceito. Também testemunha injustiças e mazelas vividas pelo povo da Cordilheira. Em seu percurso, Ernesto conhece cidades, vilas, lugares e a dura realidade da população peruana, que na sua visão de mundo, está dividido entre "os da costa" e "os da serra". 
É nesse sentido que José María Arguedas constrói seu projeto literário, vinculando-o a tentativa de denunciar a dura realidade peruana daqueles anos. "Escrevemos por amor, prazer e necessidade, não por oficio. [...] Eu vivo para escrever, e creio que é preciso viver incondicionalmente para interpretar o caos e a ordem" (ARGUEDAS, 2016, p. 43). O escritor peruano usa toda sua originalidade, para interpretar e narrar o "caos e a ordem", dando sentido histórico e político ao texto literário. Nos tópicos seguintes, será abordada a perspectiva da construção identitária de Ernesto, através da memória e da cultura.

\section{Literatura latino-americana, identidade cultural e memória}

Na América Latina o processo de construção de identidade está diretamente relacionado a um projeto histórico de colonização que ocorreu de forma abrupta, sem prévio acordo ou diálogo. Resultado dessa relação são os confrontos e instabilidades que perduram até os dias atuais. Para Octavio Paz (1989), “durante mais de três séculos a palavra americano designou um homem que não se definia pelo que havia feito senão pelo que faria, [...]. Nosso nome nos condenava a ser o projeto histórico de uma consciência estrangeira: a europeia" (PAZ, 1989, p. 17, tradução nossa). ${ }^{1}$

Para o branco europeu, a América era vista sob o signo do maravilhoso e do exótico. De certa forma incluía-se a enorme diversidade existente, mas que não devia ser considerada, apenas admirada e combatida no Novo Mundo. É somente no século XIX que se pode afirmar a existência de uma identidade cultural e mesmo uma literatura latino-americana, período em que vai ganhar um rosto. Antes disso, oscilava entre uma “certa independência” e o peso de ser cópia da Península Ibérica. O que de certa forma impedia que se fortalecesse como arte literária, com características próprias.

Para Nestor García Canclini (2008), o continente passa por uma abrupta interpenetração e coexistência de culturas, advindas das mais variadas partes do mundo. Variados processos de formação cultural desde o século XVI dão conformação a uma “mesclagem cultural”. Termos como ocidentalização, crioulização, transculturação, heterogeneidade cultural, hibridismo cultural passam a designar os processos e produtos

\footnotetext{
1 “durante más de tres siglos la palabra americano designó a un hombre que no se definía por lo que había hecho sino por lo que haría, [...]. Nuestro nombre nos condenaba a ser el proyecto histórico de una conciencia ajena: la europea" (PAZ, 1989, p. 17).
} 
resultados das novas ordens simbólicas e que fazem parte de toda essa gama cultural e identitária dos países latino-americanos.

Canclini (2008) diz que, "entendo por processo de hibridação processos socioculturais nos quais estruturas ou práticas discretas, que existiam de forma separada, se combinam para gerar novas estruturas, objetos e práticas" (CANCLINI, 2008, p. 19). Dessa forma, o resultado desse choque cultural desencadeado pelo encontro das culturas do colonizador e colonizado, e os diversos processos de invasão e ocupação, resultando em novos processos, que ele identifica como uma "heterogeneidade multitemporal” (CANCLINI, 2008, p. 74).

A busca por uma identidade própria que considerasse a enorme diversidade inserida violentamente em um projeto colonizador, fez com que o continente enfrentasse um desafio: como conciliar o local e o universal nos aspectos literários? Como dar organicidade a uma possível identidade literária e consequente uma independência do jugo ibérico? Antonio Cornejo Polar (2003) aponta que na formação da literatura latinoamericana deve se considerar um evento duplo que se destaca, conforme abaixo:

Sem dúvida a exigência de compreender a literatura latino-americana como um sistema complexo feito de variados conflitos e contradições, obriga a examinar, em primeiro lugar, o problema básico da duplicidade de seus mecanismos de conformação: a oralidade e a escrita, que é o prévio e mais profundo, e que afeta a materialidade mesma dos discursos, do que surge de situações próprias do bi ou multilinguismo e das muitas formas da diglossia. (CORNEJO POLAR, 2003, p. 19, tradução nossa). ${ }^{2}$

A oralidade e a escrita são elementos fundamentais na conformação literária do continente latino. Não resta dúvida que são as responsáveis por dar forma e vida aos mais variados discursos que surgem nas diferentes situações, visto que o continente é todo um complexo de diversidade, social, cultural e linguística. Aliada a essa perspectiva de compreensão da oralidade com a escrita apontada pelo teórico peruano, outro fator responsável nessa tentativa foi a busca por uma identidade nacional que

\footnotetext{
2 "Sin duda la exigencia a de comprender la literatura latinoamericana como un sistema complejo hecho de muy variados conflictos y contradicciones obliga a examinar, en primer término, el problema básico de la duplicidad de sus mecanismos de conformación: la oralidad y la escritura, que es previo y más profundo, en cuanto afecta o la materialidad misma de los discursos, del que surge de situaciones propias del bi o multilingüismo y de las muchas formas de la diglosia" (CORNEJO POLAR, 2003, p. 19).
} 
surge nas jovens nações americanas. A busca pela "cor local" auxiliou no projeto de construções dos Estados-nações. Machado de Assis (1873) adverte que:

\footnotetext{
Não há dúvida que uma literatura, sobretudo uma literatura nascente, deve principalmente alimentar-se dos assuntos que lhe oferece a sua região; mas não estabeleçamos doutrinas tão absolutas que a empobreçam. O que se deve exigir do escritor antes de tudo, é certo sentimento íntimo, que o torne homem do seu tempo e do seu país, ainda quando trate de assuntos remotos no tempo e no espaço. (ASSIS, 1994, vol. III, p, 3).
}

O referido texto machadiano se tornou referência para a reflexão sobre a tradição e a formação da chamada "literatura nacional" brasileira e do continente latino. É um alerta programático. Instinto de Nacionalidade é uma crítica à literatura produzida no período romântico brasileiro, mas ajuda a explicitar a posição que o escritor latinoamericano deve ater-se frente à antiga herança europeia e a constante necessidade de uma afirmação nacional.

Também Paz (1989) faz uma crítica severa e escreve da recusa de nominar as chamadas "literaturas nacionais" que surgiram a partir dos movimentos de independência política. Para ele não passam de máscaras de si mesmas, pois "o nacionalismo não é somente uma aberração moral; também é uma estética ilusória" (PAZ, 1989, p. 15, tradução nossa) ${ }^{3}$. Para o escritor mexicano, as supostas literaturas nacionais só podem ser compreendidas se fizerem parte de "um todo" latino-americano. A ideia de nação torna-se ilusória, uma farsa criada para simular uma realidade inexistente.

Sobre a literatura no continente americano, Antonio Candido (2002) adverte que "uma literatura latino-americana não passa a existir do momento em que tem condições de estilizar a realidade da América. Este é um pressuposto básico. Ela só existe quando é capaz de fecundar instrumentos de outras culturas matrizes e aplicá-los à América" (CANDIDO, 2002, p. 94). Nessa perspectiva apontada pelo crítico brasileiro, a interação entre culturas torna-se fundamental na compreensão do que será construído no Novo Mundo. Vale lembrar que não funciona como uma camisa de força ou uma lei da

\footnotetext{
3 "el nacionalismo no es solo una aberración moral; sino que también es una estética ilusoria" (PAZ, 1989, p. 15).
} 
aplicabilidade, pois deve considerar também a "imprevisibilidade" gerada do contato das várias culturas na formação identitária da América Latina.

Nesse sentido, Édouard Glissant (2005) aponta que a "imprevisibilidade" é o marco diferencial nos processos de contato entre culturas. "A imprevisibilidade cria nas Américas microclimas culturais e linguísticos absolutamente inesperados, lugares nos quais as repercussões das línguas umas sobre as outras, ou das culturas umas sobre as outras são abruptas" (GLISSANT, 2005, p. 23). Não se pode negar o choque desse contato cultural e que não foi de forma pacífica. Para entender a literatura no continente americano, Candido (2002) pressupõe ainda que:

\footnotetext{
Para estudar a literatura na América Latina há dois ângulos que podem gerar dois tipos de teorias e metodologias. Ambos são válidos e não devem ser considerados mutuamente exclusivos; e sim correspondentes a dois "momentos" dialéticos do processo global: a) a literatura como prolongamento das literaturas metropolitanas - b) como ruptura em relação a elas. (CANDIDO, 2002, p. 99).
}

De qualquer forma, a obra crítica desses autores traz a perspectiva de universalidade da literatura latino-americana, ao mesmo tempo que a coloca com as características locais do "regionalismo continental". Não há como negar um distanciamento total da herança europeia nas produções literárias. Além disso, a influência sofrida pelas constantes diásporas na América, levou a conformação cultural e identitária que ainda não se pode definir com precisão. O termo "imprevisível" destacado por Glissant (2005) parece condensar tudo que o continente latino vive até os dias atuais.

Por sua vez, Paz (1981) aponta que a identidade cultural na América só começa a ganhar um rosto a partir do movimento modernista, pois para ele, "até a aparição dos modernistas, não era fácil perceber as características originais da literatura hispanoamericana" (PAZ, 1981, p. 27, tradução nossa) ${ }^{4}$. Isso só vai acontecer no século XIX, com o advento da Modernidade, mesmo no período independentista, com a ânsia de se

\footnotetext{
4 "hasta la aparición de los modernistas no era fácil percibir rasgos originales en la literatura hispanoamericana" (PAZ, 1981, p. 27).
} 
criar identidades nacionais, como vimos anteriormente, estas eram apenas ilusórias, segundo o próprio Octavio Paz (1981).

O que parece ser comum aos teóricos acima mencionados no que se refere aos estudos de literatura latino-americana e sua formação é a ruptura com um estudo sistemático e tradicional, como se a América só passasse a existir com a chegada do branco colonizador. Existiam civilizações e formas de vida, produções de saberes, produções artísticas, culturais e literárias que possuíam valor estético considerável. O Popol Vuh, dos Maias-quiche da América Central, é um exemplo de produção que pela oralidade chegou ao colonizador que compilou as narrativas da cosmovisão dos povos originários dessa região.

Pensar em identidade latino-americana e sua literatura deve-se considerar que todo o emaranhado cultural existente no continente é resultado dos processos históricos de ocupação e dos contatos entre as diversas culturas que aqui desembarcaram. Como aponta Cornejo Polar (2000), "a consciência de que nossa literatura é produto de vários e antagônicos sujeitos sociais, com linguagens, racionalidades e imaginários discordantes" (CORNEJO POLAR, 2000, p. 51).

A identidade está relacionada com a memória, pois no contexto latinoamericano, os diversos grupos sociais têm nela a garantia da manutenção de suas tradições culturais. Tome-se por exemplo os contadores de histórias, narradores, "os homens-memórias", que se utilizam dos mecanismos memorialísticos para abordar diferentes temas, contar e recontar narrativas, histórias de vida e do grupo social, os mitos e as lendas. Por sua vez, a relação entre a memória e a literatura é algo que supõe um entrelaçamento fecundo. E a partir dessa relação, que os eventos de cunho memorialísticos, contribuem para um dinamismo e profundidade ao fazer literário.

Cabe aqui mencionar que para Henri Bergson (1999), a memória compõe-se de dois aspectos principais: mobilidade e criatividade. É justamente ela que garante a unidade do mundo material ao mundo espiritual. Ou seja, não é puro armazenamento de coisas e imagens. A memória atua em dois planos para Bergson, o plano da ação, que está relacionado ao corpo que contrai o passado em hábitos de rememoração, e o plano da memória pura, em que se conserva eventos na forma de imagens de tudo que transcorreu. 
Nesse sentido, há um elo significativo entre a memória e a literatura, pois são potências vivas da experiência humana. A memória se desdobra em imagens, e o artista é capaz de compreender esta relação, lançando mão em sua escritura desse mecanismo, sendo ao mesmo tempo construção e construtor. Para Paul Ricoeur (2007) é através da linguagem "retrabalhada com a ajuda de ferramentas de uma semântica e de uma pragmática do discurso, [que ela, linguagem] oferece aqui uma ajuda preciosa, com a atribuição das operações psíquicas a alguém" (RICOEUR, 2007, p. 134). A memória assim entendida, atua como um fio condutor, produtora de discursos.

Ao tratar da perspectiva individual e/ou coletiva da memória, Ricoeur (2007) aponta para uma "atribuição múltipla", o que pressupõe incluir uma relação entre tais perspectivas, num movimento de saída do caráter individual da memória em direção ao aspecto coletivo. Dessa forma, é possível que as marcas da memória pessoal se transformem em características da memória coletiva.

No romance Os rios profundos, o narrador-personagem Ernesto, quando recorre à memória, recorda fatos e acontecimentos por ele vividos, mas que se entrelaçam a outros personagens da narrativa, criando imagens na coletividade.

Para Ricoeur, é a partir da relação pessoal dentro dos grupos sociais que ambas memórias - individual e coletiva - se fortalecem. Nesse sentido, percebe-se a relação intrínseca com a linguagem.

É essencialmente no caminho da recordação e do reconhecimento, esses dois fenômenos mnemônicos maiores de nossa tipologia da lembrança, que nos deparamos com a memória dos outros. Nesse contexto, o testemunho não é considerado enquanto proferido por alguém para ser acolhido por outro, mas enquanto recebido por mim de outro a título de informação sobre o passado. (RICOEUR, 2007, p. 131).

Há, para Ricoeur, um papel importante da linguagem como portadora da memória. Torna-se essencial nos grupos sociais, pois as manifestações memorialísticas são constituídas, integradas e modificadas por ela. Dessa forma, estão no plano coletivo, onde também se encontra o sujeito/indivíduo da lembrança. É a linguagem que dá suporte ao entrelaçamento entre o privado e o público no âmbito da memória. 
A linguagem transmuta-se em um instrumento de interação, tornando-se um enunciado. É uma atividade característica do ato de comunicação como uma manifestação da vida, do espírito humano e é uma atividade essencial, como as artes e a literatura. Nesse sentido, a narrativa utiliza-se da língua, de forma a envolver a experiência humana às questões da temporalidade. Essa temporalidade surge em ações narrativas, sejam elas históricas ou ficcionais.

De fato, no que se refere à literatura de Arguedas, Gustavo Martinez (2009) aponta que o escritor peruano traz em sua obra as marcas da construção identitária fragmentada por dois mundos. Aliada a mecanismos linguísticos, entre eles, o discurso memorialístico, ele afirma que "o Peru de J.M. Arguedas é um mundo fraturado e polarizado em todos os níveis. Em primeiro lugar, porque de lá brotam todas as demais rupturas" (MARTÍNEZ, 2009, p. 2, tradução nossa) ${ }^{5}$.

Essa fratura deve ser considerada ao pensar na composição cultural e identitária da América Latina, bem como na formação de sua literatura, sob pena de cair em velhos enganos de uma identidade pura e original, e/ou de uma cultura única. O que não é verdade. A mistura étnica e cultural que se dá na narrativa arguediana, aliada a inserção de eventos de cunho mnemônicos, é a linha mestra que direciona o texto literário do escritor peruano.

\section{Arguedas e Ernesto: a construção da identidade cultural através da memória}

No romance Os rios profundos (2005), o narrador-personagem é Ernesto, que adulto, evoca pela memória, fatos e eventos de sua infância e adolescência. "Eu tinha catorze anos: passara minha infância numa casa estranha, sempre vigiado por pessoas cruéis" (ARGUEDAS, 2005, p. 23). Ernesto conta com detalhes e pormenores suas aventuras, peripécias e intempéries vividas ao lado do pai, quando viajavam pela Cordilheira dos Andes, a procura de trabalho. Seu pai, é um advogado itinerante. Percebe-se que a narrativa não é simplesmente descritiva dos eventos, espaços e lugares, e nem superficial; pelo contrário, ela é densa e profunda.

\footnotetext{
5 "el Perú de J. M. Arguedas es un mundo fracturado y polarizado a todos los niveles. En primer lugar, porque de allí brotan todas las demás escisiones". (MARTíNEZ, 2009, p. 2).
} 
No livro, boa parte da narrativa transcorre com Ernesto no colégio interno em Abancay, cidade peruana situada na Cordilheira andina. "Abancay está cercada pelas terras da fazenda Pitibamba. E todo o vale, de norte a sul, de um pico a outro, pertence às fazendas" (ARGUEDAS, 2005, p. 55). Na escola, assim como nas viagens, o personagem Ernesto constrói uma reflexão sobre o que é ser peruano, o que é ser indígena e o que é ser mestiço/híbrido/heterogêneo, tudo o afeta profundamente:

\begin{abstract}
Naqueles dias de confusão e desassossego, lembrava-me do canto de despedida que as mulheres me dedicaram, no último ayllu $u^{6}$ onde morei, como refugiado, enquanto meu pai vagava perseguido. Fugindo de parentes cruéis, pedi misericórdia a um ayllu que plantavam milho na menor e mais alegre quebrada que conheci. (ARGUEDAS, 2005, p. 57).
\end{abstract}

A consciência de Ernesto o leva a perceber que ele faz parte de um todo "mesclado". De família branca, mas que por motivos políticos e perseguição ao seu pai, a família perdera os bens. Nesse itinerário empreendido, aos poucos se dá conta da diversidade que o cerca. No fragmento, percebe-se o quanto foi importante para construção identitária de Ernesto, o fato dele ter convivido com os indígenas. Foi com eles que aprendeu a falar quéchua e onde aprendeu "a música, os cantos e o falar dulcíssimo das criadas índias e dos concertados" "(ARGUEDAS, 2005, p. 11).

O primeiro capítulo do romance intitula-se $O$ velho e traz a representação emblemática do tio do pai de Ernesto. O velho representa a avareza de um grande proprietário de terras e animais, com muitos $\operatorname{pongos}^{8}$ a sua disposição. Fica evidente a estrutura social a que estava condicionada a população indígena, que era explorada e expropriada, por seus próprios conterrâneos; tal constatação pode se traduzir como disputa e manutenção do poder local pela exploração do outro. "Depois, quando meu pai me resgatou e comecei a vagar com ele pelos povoados, vi que em toda parte as pessoas sofriam" (ARGUEDAS, 2005, p. 23). Chama a atenção a posição crítica de

\footnotetext{
${ }^{6}$ Comunidades de índios. A base da produção agrícola dos incas era o ayllu, uma comunidade formada por pessoas que acreditavam na descendência única, ou seja, cada ayllu era reconhecida como uma grande família.

${ }^{7}$ São peões que trabalhavam nas fazendas com salário anual.

8 Índios que viviam nas fazendas como serviçais em troca de refeições e/ou hospedagem, não possuíam salários, nem propriedades.
} 
Ernesto que aciona a memória para um narrar com o objetivo de descrever a dura realidade.

Esse capítulo também traz a entrada simbólica dos viajantes na cidade de Cusco, capital do antigo império Inca. Sempre atento, Ernesto analisa tudo internamente, desde as rochas que compõe o muro incaico, as ruas, as praças e arquitetura da cidade. Observa os sentimentos que percebe no pai, e reflexiona no sentido de entender o que está acontecendo. Considerada como o "umbigo do mundo", a cidade de Cusco é emblemática por natureza. Guarda singularidades que fazem com que os personagens passem por momentos de profunda reflexão, deslocamentos e devires incertos.

A cidade de Cusco é a perfeita representação das diversas identidades que dialogam. A tradição e a modernidade se entrecruzam. É na cidade que encontramos a representação da igreja, do Estado e das culturas ameríndias ainda vivas, todas no mesmo espaço urbano, se chocam e estabelecem relações diversas e múltiplas.

\footnotetext{
Era noite quando entramos em Cusco. Fiquei surpreso com a estação de trem e a avenida larga pela qual, lentamente, avançávamos. A luz elétrica era mais fraca que a de alguns lugarejos que eu conhecia. Grades de madeira ou de aço defendiam jardins e casas modernas. A Cusco de meu pai, aquela que ele me descrevera umas mil vezes, não podia ser essa. (ARGUEDAS, 2005, p. 8).
}

Ernesto não reconhece a Cusco descrita anteriormente pelo pai. Nesse momento as lembranças do personagem são ativadas. Existe um estranhamento que o desconforta e o desloca no confronto em diferentes perspectivas. A cidade era bem maior que imaginava, pois possuía elementos da modernidade ainda não vistos por ele, diferentes das que tinha presenciado em viagens anteriores. Nesse sentido, Stuart Hall (2006) aponta para uma crise de identidade como sendo "parte de um processo mais amplo de mudança, que está deslocando as estruturas e processos centrais das sociedades modernas e abalando quadros de referência” (HALL, 2006, p. 7).

Ernesto, que vive suas contradições, esperava encontrar "uma Cusco" voltada para a tradição da cultura incaica, justamente por ter sido a capital do "grande império Inca". Para ele, era como se a cidade tivesse que manter traços originais da cultura nativa, ter mantido em seus espaços elementos culturais indígenas, mas não é isso que constata. O que encontra é uma cidade que inicia um processo de modernização, ruas e 
avenidas largas, praças, luz elétrica, movimentação de pessoas que se deslocam dos lugares. Diferente do que imaginava e do tinha como referência em sua memória reconstruída e compartilhada com o seu pai.

O pai de Ernesto também passa por um processo de não reconhecimento de si e da cidade. "Meu pai ia se escondendo junto às paredes, na sombra. Cusco era sua cidade natal, e não queria que o reconhecessem" (ARGUEDAS, 2005, p. 8). A identidade nesse momento passa por uma busca de "ancoragem". Algo que dê suporte para manterse firme. Como conciliar tal deslocamento, dentro de um processo de mudança estrutural avassalador, como foi a modernidade em muitos lugares?

Vale ressaltar a diferenciação e ruptura entre sociedades modernas e sociedades tradicionais, como esclarece Stuart Hall que "as sociedades modernas são, portanto, por definição, sociedades de mudança constante, rápida e permanente. Esta é a principal distinção entre sociedades "tradicionais" e as "modernas" (HALL, 2006, p. 14).

O resultado é uma construção identitária baseada na fragmentação e no deslocamento. O sujeito ficcional fica em um "entre lugar", entre o ser e o tornar-se, constituído pela linguagem. Nesse sentido, o romance reconstrói o resultado da conformação ocorrida, desde os primeiros processos de ocupação no continente americano, as lutas por territórios das antigas civilizações pré-colombianas, passando pela chegada do branco europeu e pelos inúmeros movimentos migratórios, forçados ou não, ocorridos na América Latina.

Arguedas, em Os rios profundos, narra a partir dessa mistura de culturas, que são mestiças, híbridas e heterogêneas. Acrescenta ao seu estilo literário, os aspectos identitários que se movimentam em territorialidades múltiplas e imprevisíveis. O papel do escritor foi dar ressignificado a esse emaranhado de elementos. Seus personagens puderam atribuir um novo sentido a acontecimentos de mudança, a partir de sua visão de mundo. Tudo é constantemente alimentado pelos espaços, tradições, costumes e pela linguagem, onde o quéchua e o castelhano disputam territórios no decorrer da obra.

Um dos mecanismos usados no estilo arguediano de construir sua narrativa é a memória. Por ela há uma tentativa de reconstrução do passado. Tal passado ficou para trás no tempo, mas está guardado na memória. Através dela é possível obter imagens dos fatos e eventos ocorridos. Não é tudo que se pode presentificar na hora de evocar as lembranças: "em outras palavras, é do presente que parte o apelo ao qual a lembrança 
responde, e é dos elementos sensório-motores da ação presente que a lembrança retira o calor que lhe confere vida" (BERGSON, 1999, p. 179).

A lembrança é uma escolha do sujeito, do querer lembrar. Paul Ricouer (2007) enfatiza que a memória traz aspectos que estão relacionados com o caráter cognitivo e o caráter pragmático acerca dos termos gregos mnèmè e anamnèsis, ou seja, é como ter uma lembrança e/ou ir em busca de uma lembrança. Dessa maneira, surgem as perguntas “o que?" e "como?" escolher os eventos mnemônicos.

$\mathrm{Na}$ literatura, é através da escrita que o autor propõe decifrar os eventos de cunho memorialístico, e atribui essa tarefa ao personagem através do discurso narrativo. Essa atitude é uma forma de garantir unicidade ao discurso do narrador-personagem no presente. Dessa forma, Ernesto conhece cidades e vilas paupérrimas em suas viagens, tomadas por casas muito pobres, que em geral pertenciam aos grandes e ricos fazendeiros. Em geral homens brancos e/ou criollos ${ }^{9}$. Ele se encanta com a profundidade, grandeza e força dos rios. São como pontes sobre o mundo, são linhas que dividem o Peru em dois mundos, dos brancos e dos índios, da costa e da serra.

No capítulo As viagens (ARGUEDAS, 2005, p. 33), o narrador-personagem relembra os diversos lugares que conheceu, descreve vilas e povoados, rios e montanhas. O espaço é essencial na construção da narrativa:

\footnotetext{
Meu pai nunca encontrou lugar onde fixar residência; foi um advogado de províncias, instável e errante. Com ele conheci mais de duzentos povoados. Temia os vales quentes e só passava por eles como viajante; ficava algum tempo nos povoados de clima temperado: Pampas, Huaytará, Coracora, Puquio, Andahuaylas, Yayuos, Cangallo... Sempre junto de um rio pequeno, sem bosque, com grandes pedras luzidias e peixes miúdos”. (ARGUEDAS, 2005, p. 33).
}

É a memória que permite estabelecer as muitas relações de vivências, experiências individuais e/ou coletivas que permanecem gravadas para se presentificar no discurso do narrador-personagem. Ela liga as lembranças anteriores ao presente, estabelece um vínculo. "Mas meu pai decidia partir de um povoado para outro quando as montanhas, os caminhos, os campos de jogo, o pouso dos pássaros, quando os

\footnotetext{
${ }^{9}$ O termo criollo é usado para designar os descendentes de espanhóis que eram nascidos na América hispânica. Em geral eram possuidores de grandes propriedades e também atuavam no comércio.
} 
detalhes do povoado começavam a fazer parte da memória" (ARGUEDAS, 2005, p. $34)$.

Aliada aos processos mnemônicos dos personagens encontramos a temporalidade dos eventos. São eventos externos ao corpo, mas estão intimamente ligados. Esta relação entre tempo e memória é importante para entender como a capacidade de percepção das coisas acontece e como ficarão armazenadas, para serem evocadas quando por necessidade ou impulsividade, sejam chamadas a emergir. Para Bergson (1999), a lembrança é "a representação de um objeto ausente" (p. 80). Em outras palavras, “a memória, praticamente inseparável da percepção, intercala o passado no presente" (BERGSON, 1999, p.77).

Dessa forma, a memória ajuda a construir identidades. Estão relacionadas de forma peculiar. As lembranças e eventos passados, remetem naturalmente à construção identitária do sujeito: espaço e tempo ganham dimensões transcendentais. O pai de Ernesto se mudava quando aquele lugar e tudo que acontecia "começavam a fazer parte da memória" (ARGUEDAS, 2005, p. 34).

\footnotetext{
Nos povoados, em determinada hora, as aves se dirigem, visivelmente, a lugares já conhecidos. Vão para os pedregais, os pomares, os arbustos que medram à margem das aguadas. $\mathrm{E}$, conforme o tempo, seu voo é diferente. $\mathrm{O}$ pessoal do lugar não observa tais detalhes, mas os viajantes, aqueles que vão partir, não se esquecem deles. (ARGUEDAS, 2005, p. 35).
}

A construção identitária de Ernesto torna-se itinerante. A memória também acompanha esse movimento. Ambas se deslocam com o sujeito do discurso, que está em constante construção. Nesse percurso de viagens, o personagem busca elementos que possa se identificar. A voz narrativa retorna ao passado ou marca uma evocação para estabelecer a conexão com o seu "eu" sujeito no presente. Usa a memória para fazer digressões e reflexões, cheia de sentimentos, alegres ou tristes.

A construção de uma identidade móvel/mesclada do personagem deve-se ao que foi tratado na primeira parte do artigo. A partir da invasão e ocupação espanhola no espaço andino, o resultado é uma conformação cultural nova e "imprevisível", dando esse caráter mesclado e heterogêneo aos sujeitos. As populações tradicionais foram hispanizadas a força, chamados de "índios", foram marcados como selvagens e/ou 
bárbaros. O espaço andino foi fragmentado, seus moradores despojados de suas terras e submetidos à exploração e servidão:

\begin{abstract}
Durante séculos, as culturas europeias e indígena conviveram em um mesmo território em incessante reação mútua, influenciando a primeira sobre a outra com os crescentes meios que sua potente e incomparável dinâmica oferece; e a indígena defendendo-se e reagindo graças ao encaixe interior que não havia sido quebrado e graças ao que continua em seu meio nativo; nestes séculos, não somente uma interveio sobre a outra, senão que como resultado da incessante reação mutua apareceu um personagem, um produto humano que está aparecendo como uma atividade poderosíssima, cada vez mais importante: o mestiço. (ARGUEDAS, 1975 apud TEJEDA, 2012, p. 79, tradução nossa)..$^{10}$
\end{abstract}

No romance, o valor da representação simbólica da mescla de culturas acontece a partir da linguagem. Uma perfeita simbiose entre o mundo objetivo e o subjetivo. A mistura de duas raças e/ou culturas resulta em diferentes visões de mundo e consequentemente diferentes formas de produção discursiva. Arguedas escolhe o plurilinguismo e a multiculturalidade. Constata-se na narrativa uma forte presença da oralidade da língua quéchua, sua cosmovisão e elementos culturais marcantes.

A língua do colonizador serve como estratégia para produções de significado dos elementos simbólicos indígenas. O sexto capítulo, por exemplo, traz o zumbayllu ${ }^{11}$. Um brinquedo mágico, que vai além de uma atividade lúdica. Ele é carregado de simbologias, trazendo na sua essência a alma indígena, com uma carga sincrética de anjos, deuses e demônios:

\footnotetext{
Antero veio correndo e nos encontrou ao pé da escada.

- O winku, irmão! - gritou - Winku e layk'a como nunca se viu!

Mostrou um zumbayllu cinza escuro, com resplendores vermelhos.
}

\footnotetext{
10 "Durante siglos, las culturas europeas e india han convivido en un mismo territorio en incesante reacción mutua, influyendo la primera sobre la otra con los crecientes medios que su potente e incomparable dinámica le ofrece; y la india defendiéndose y reaccionando gracias a que su ensamblaje interior no ha sido roto y gracias a que continúa en su medio nativo; en estos siglos, no sólo una ha intervenido sobre la otra, sino que como resultado de la incesante reacción mutua ha aparecido un personaje, un producto humano que está desplegando una actividad poderosísima, cada vez más importante: el mestizo" (Arguedas, 1975, p. 2, apud TEJEDA, 2012, p. 79).

${ }^{11}$ Espécie de pião feito de madeira, também chamado de trompo na língua espanhola.
} 
[...] - Este é uma mistura de anjo com bruxos - disse - Layk'a por seu fogo e winku por sua forma, diabos; mas Salvinia também está nele. Eu cantei seu nome enquanto pregava a ponta e queimava os olhos do zumbayllu. (ARGUEDAS, 2005, p. 158, 160).

Em outro trecho tem-se a explicação do narrador-personagem do que significa $y l l u$. A voz narrativa mostra que não é uma explicação simples de pura tradução, vai além, é profunda e está inserida na cosmovisão de quem conhece o significado simbólico:

A terminação quéchua yllu é uma onomatopeia. Yllu representa uma das suas formas da música que se produzem de pequenas asas em um voo; música que surge do movimento de objetos leves. Esta voz tem semelhança com outra mais vasta: illa. Illa dá nome a certa espécie de luz e aos monstros que nasceram feridos pelos raios da lua. Illa é um nome de um menino de duas cabeças ou um bezerro que nasce decapitado, ou um penhasco gigante, todo negro e firme, cuja superfície aparece cruzada por uma veia larga de rocha branca, de opaca luz [...] são Illas os touros míticos que habitam o fundo dos lagos solitários [...] Se chama tankayllu, a mosca de zumbido inofensivo que voa os campos [...] pinkuyllu é o nome da quena gigante que tocam os índios do sul durante as festas comunitárias. O pinkuyllu não se toca jamais em festas familiares. (ARGUEDAS, 2005, p. 88).

Ganha importância o fato de Ernesto explicar os termos quéchuas, usando a língua do colonizador espanhol. Isso só é possível porque ele possui um conhecimento da língua incaica e sua cultura, pois transita e se movimenta nos dois códigos linguísticos. Ernesto não substitui o termo por outro pertencente à língua espanhola, porque sabe que as palavras em quéchuas veiculam representações simbólicas que são inerentes à cultura indígena e, portanto, expressam vinculação com as coisas, com a natureza, com a vida, com o mundo sensível.

Dessa forma, no plano enunciativo, o sujeito narrador-personagem configura-se como um sujeito fragmentado e heterogêneo. Ele conhece e transita por duas culturas “opostas". Alguém que lê e escreve em espanhol, mas conhece a língua incaica, do qual também compartilha e constrói sua identidade a partir dela, pois a conhece em 
profundidade. Durante a brincadeira do zumbayllu, os meninos jogam e fazem uma disputa, mas brotam inúmeras possibilidades de interação entre os jogadores e o objeto:

Zumbayllu! No mês de maio. Antero trouxe o primeiro zumbayllu ao colégio. Os alunos pequenos o rodearam.

- Zumbayllu, Zumbayllu!

Eu os segui ansiosamente. (ARGUEDAS, 2005, p. 92).

O místico e o simbólico representados pelo zumbayllu significa uma voz, um espírito, um "grito poético". Ele canta quando é jogado para rodar. Percebe-se uma mistura de sensações, devaneios e devires que deslocam Ernesto e sua identidade por várias direções. O pião proporciona tais sensações, "o canto do zumbayllu penetrava no ouvido, avivava na memória a imagens dos rios, das árvores pretas que pendem das paredes dos abismos" (ARGUEDAS, 2005, p. 94). Vale lembrar o que Cornejo Polar (2003) fala da identidade do sujeito:

Dessa maneira a identidade do sujeito se extravia em uma palavra que é sua e de muitos. Na beira de dois mundos, o oral e o escrito, romance e canção, moderno e antigo, urbano e camponês, espanhol e quéchua, o sujeito e sua aptidão discursiva não tem outra possibilidade que misturar-se com o todo o povo quebrado e misturado. (CORNEJO POLAR, 2003, p, 195, tradução nossa). ${ }^{12}$

A experiência entre a cosmovisão indígena e a cultura do colonizador produz um tecido vital que dá densidade à escritura literária de José María Arguedas. Não é uma sucessão de fatos e eventos, muito menos processos descritivos de uma realidade. No romance Os rios profundos a grandeza e profundidade da obra é marcada por essa simbiose que fica evidente no discurso de Ernesto. Que tipo de sujeito ele é? Branco e/ou índio? Mestiço e heterogêneo? Alguém que vive entre dois mundos e transita entre

\footnotetext{
${ }^{12}$ De esta manera la identidad del sujeto se extravía en una palabra que es suya y de muchos. En el borde de dos mundos, oral y escrito, novela y canción, moderno y antiguo, urbano y campesino, español y quechua, el sujeto y su aptitud discursiva no tienen otra posibilidad que entreverarse con todo un pueblo quebrado y heteróclito. (CORNEJO POLAR, 2003, p, 195).
} 
a oralidade e a escrita, gerando uma narrativa discursiva que enriquece a obra literária arguediana.

Viver em dois mundos completamente diferentes, fez com que Ernesto seja um sujeito fragmento e deslocado. Alguém que a todo momento busca elementos que lhe sirvam de apoio para definição de sua identidade cultural. Arguedas o auxilia em sua trajetória através da memória individual e/ou coletiva produzida pelas relações vividas por ele ao lado do pai, dos indígenas do ayllu, dos amigos e colegas do colégio interno em Abancay.

\section{Considerações finais}

O presente artigo é fruto de uma leitura e reflexão da obra arguediana com o objetivo que compreender sua riqueza literária, atentando para a força da memória e da identidade cultural no romance Os rios profundos. Para tanto, é imprescindível conhecer o processo histórico, político, econômico, social e principalmente cultural de como foi formada a cultura no continente americano, em especial, dos países que foram colonizados pelos espanhóis e a apropriação dos territórios, antes ocupados por várias civilizações autóctones, em especial, a civilização Inca.

Verifica-se que os contextos são historicamente marcados pelo confronto e pela ruptura. O projeto colonizador, apesar de aparentar vitorioso, enfrentou resistência de vários movimentos. José María Arguedas coloca a literatura como parte dessa luta contra o jugo do branco europeu. "Eu não sou aculturado", dizia ele. E sua literatura foi a tentativa clara de romper com a empreitada europeia. Ele produziu uma literatura que transita entre o localismo e a universalidade, entre a cultura indígena e a cultura do colonizador. A estratégia usada é justamente pela linguagem que ele se apropria para produção de uma narrativa com marcas e características latino-americanas.

O narrador-personagem Ernesto é a representação do novo, do imprevisível. Ernesto enfrenta uma verdadeira saga em direção da sua própria aceitação e passa por um processo de aprendizagem e conhecimento interno. É o resultado mais bem elaborado do choque entre as duas culturas: um personagem mestiço, heterogêneo, híbrido, crioulo. Sua voz ecoa pelos rios e vales, vilarejos e montanhas da Cordilheira dos Andes. O espaço é significativo na construção identitária de Ernesto que nos 
limiares da memória faz-se linguagem - literatura. Alçando o indivíduo ao sujeito, o afeto à memória, o existir à identidade e a poética à estética.

\section{REFERÊNCIAS}

ARGUEDAS, José María Arguedas. Os rios profundos. Trad. Josely Vianna Baptista. São Paulo: Companhia das Letras, 2005.

ARGUEDAS, José Maria Arguedas. A raposa de cima e a raposa de baixo. Trad. Rômulo Monte Alto. Belo Horizonte: Editora UFMG, 2016.

ASSIS, Machado de. Notícia da atual literatura brasileira. Instinto de nacionalidade. In: Obra Completa. Vol. III, Rio de Janeiro: Nova Aguilar, 1994.

BERGSON, Henri. Matéria e memória: ensaios sobre a relação do corpo como espírito. Trad. de Paulo Neves. 3. ed. São Paulo: Martins Fontes, 1999.

CANCLINI, Néstor García. Culturas híbridas - Estratégias para entrar e sair da modernidade. Trad. Heloísa Pezza Cintrão e Ana Regina Lessa. $4^{\mathrm{a}}$ ed. São Paulo: EDUSP, 2008.

CANDIDO, Antonio. Textos de Intervenção. São Paulo: Duas cidades; Ed.34, 2002.

CORNEJO POLAR, Antonio. Escribir en el aire. Lima: CCELACP-latinoamericana Editores. $2^{\text {a }}$ Edición, 2003.

CORNEJO POLAR, Antonio. O condor voa: literatura e cultura latino-americanas. Organização de Mario J. Valdés. Trad. de Ilka Valle de Carvalho. Belo Horizonte: UFMG, 2000. (Col. Humanitas).

GLISSANT. Édouard. Introdução a uma poética da diversidade. Trad. de Enilce do Carmo Albuquerque Rocha. Juiz de Fora: Editora UFJF, 2005.

HALL, Stuart. A identidade cultural na Pós-Modernidade. Rio de Janeiro: DP\&A Editora, 2006.

MARTÍNEZ, Gustavo. Espacio, identidad y memoria en Los ríos profundos de J. M. Arguedas. Revista Humanidades. Montevideo: Año VIII-IX.1. Dezembro de 2008. p. 43-58. Disponível em: http://www.um.edu.uy/docs/revista_fhum_8y9_martinez.pdf. Acesso em 20 de junho de 2020. 
PAZ, Octavio. Literatura de fundación. In: Puertas al campo. Barcelona. Seix Barral. 1989.

PAZ, Octavio. Alrededores de la literatura hispanoamericana. In: Mediaciones. 2. ed. Barcelona: Editorial Seix Barral, 1981. p. 25-37.

REIS, Lívia Maria de Freitas. Transculturação e Transculturação Narrativa. In:

Figueiredo, Eurídece (org). Conceitos de literatura e cultura. Niterói: Editora da UFF, 2005. p. 465-488.

RICOEUR, Paul. A memória, a história, o esquecimento. Trad. Alain François et. al. Campinas: Editora Unicamp, 2007.

TEJEDA, Nelson Osorio. José María Arguedas y el lenguaje de la identidad mestiza. In: Revista América sin nombre, Alicante: $n^{\circ} 17$. p. 75-80, 2012. Disponível em: https://rua.ua.es/dspace/bitstream/10045/26476/1/ASN_17_09.pdf. Acesso em: 10 de junho de 2020. 